\title{
Unmet Needs in the Treatment of Gastroesophageal Reflux Disease
}

\author{
Ram Dickman, Carla Maradey-Romero, Rachel Gingold-Belfer, and Ronnie Fass* \\ The Esophageal and Swallowing Center, Division of Gastroenterology and Hepatology, MetroHealth Medical Center, Case Western Reserve \\ University, Cleveland, Ohio, USA
}

Gastroesophageal reflux disease (GERD) is a highly prevalent gastrointestinal disorder. Proton pump inhibitors have profoundly revolutionized the treatment of GERD. However, several areas of unmet need persist despite marked improvements in the therapeutic management of GERD. These include the advanced grades of erosive esophagitis, nonerosive reflux disease, maintenance treatment of erosive esophagitis, refractory GERD, postprandial heartburn, atypical and extraesophageal manifestations of GERD, Barrett's esophagus, chronic protein pump inhibitor treatment, and post-bariatric surgery GERD. Consequently, any future development of novel therapeutic modalities for GERD (medical, endoscopic, or surgical), would likely focus on the aforementioned areas of unmet need.

(J Neurogastroenterol Motil 2015;21:309-319)

\section{Key Words}

Gastroesophageal Reflux; Heartburn; Proton Pump Inhibitors

\section{Introduction}

Gastroesophageal reflux disease (GERD) is a chronic and highly prevalent medical problem. Population-based studies have demonstrated that $44 \%$ and $20 \%$ of the US adult population reported GERD-related symptoms (heartburn and acid regurgitation) at least once a month and once a week, respectively. ${ }^{1}$ Most patients with GERD fall into one of 3 categories: nonerosive reflux disease (NERD), erosive esophagitis (EE), and Barrett's esophagus (BE). The 2 main phenotypes of GERD (NERD and
EE) appear to have different pathophysiological and clinical features and, most importantly, differ in their response to antireflux treatment. ${ }^{2}$ The goal of antireflux treatments is to effectively relieve GERD-related symptoms, heal and maintain remission of $\mathrm{EE}$, prevent complications of GERD, and improve health-related quality of life.

Currently, proton pump inhibitors (PPIs) and histamine type 2 receptor antagonists (H2RAs, albeit with lower potency) represent the cornerstone of GERD treatment. It has been demonstrated that PPIs achieve a profound inhibitory effect on gastric acid secretion that results in high rates of esophageal mucosal

Received: June 15, 2015 Revised: June 17, 2015 Accepted: June 18, 2015

(c) This is an Open Access article distributed under the terms of the Creative Commons Attribution Non-Commercial License (http://creativecommons. org/licenses/by-nc/4.0) which permits unrestricted non-commercial use, distribution, and reproduction in any medium, provided the original work is properly cited.

${ }^{*}$ Correspondence: Ronnie Fass, MD, FACG

Esophageal and Swallowing Center, Division of Gastroenterology and Hepatology, MetroHealth Medical Center, Case Western Reserve University, 2500 MetroHealth Drive, Cleveland, OH 44109, USA Tel: +1-216-778-3145, Fax: +1-216-778-2074, E-mail: Ronnie.fass@gmail.com

Financial support: None.

Conflicts of interest: None.

Author contributions: Ram Dickman, Carla Maradey-Romero, Rachel Gingold-Belfer, and Ronnie Fass drafted and developed the manuscript.

ORCID: Ram Dickman, http://orcid.org/0000-0002-6477-2849; Carla Maradey-Romero, http://orcid.org/0000-0003-3900-8598; Rachel Gingold-Belfer, http://orcid.org/0000-0002-2831-4402; Ronnie Fass, http://orcid.org/0000-0002-4807-3052. 
healing and effective (as well as durable) control of GERD-related symptoms. 3

Despite the marked developments in medical, endoscopic, and surgical therapy, there are still many areas of unmet need in the treatment of GERD. Advanced grades of EE (Los Angeles grades C [LA-C] and D [LA-D]) demonstrate the lowest healing rates in patients on PPI once daily. Patients with NERD often fail to respond adequately to PPI treatment. Moreover, the current clinical experience in the treatment of atypical and extraesophageal manifestations of GERD (eg, noncardiac chest pain $[\mathrm{NCCP}]$, chronic cough, and hoarseness) has been profoundly disappointing. Unfortunately, most PPI therapeutic trials in patients with pharyngeal, laryngeal, or pulmonary symptoms (presumed to be GERD related) have failed to demonstrate any benefit over placebo.

Other areas of unmet need in GERD treatment include nighttime and postprandial heartburn, refractory GERD, maintenance treatment of EE, on-demand or intermittent therapy for GERD, BE, chronic PPI treatment, and post-bariatric surgery GERD (Table 1).

\section{Advanced Grades of Erosive Esophagitis}

Systematic reviews of epidemiological studies have revealed that the prevalence of reflux esophagitis in patients with GERD is between $10 \%$ and $25 \%$ in Western countries and between $5 \%$ and $17 \%$ in Asian and Pacific countries. ${ }^{5-9}$ The prevalence of advanced EE (LA-C and LA-D) in elderly GERD patients may reach $37 \% .{ }^{10}$ However, most studies demonstrated a range be-

Table 1. The Unmet Needs in Treatment of Gastroesophageal Reflux Disease

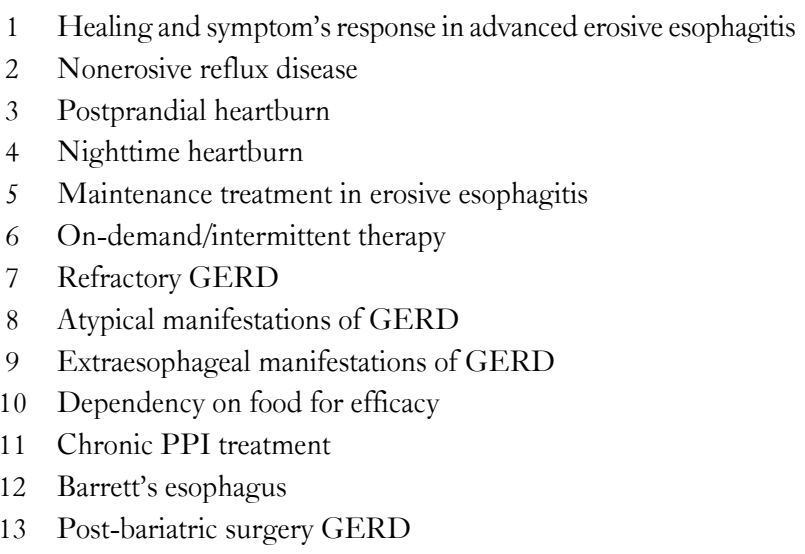

GERD, gastroesophageal reflux disease; PPI, proton pump inhibitor. tween $15 \%$ and $30 \% .^{8,9,11-14}$

Advanced grades of $\mathrm{EE}$ are considered an area of unmet need in GERD because of relatively low symptomatic response and healing rates as well as a higher relapse rate, even with continuation of the initial healing dose of PPI. ${ }^{13}$ Overall, studies have reported that approximately $4 \%$ to $15 \%$ of patients with $\mathrm{EE}$ fail to achieve complete healing of esophageal inflammation after 8 weeks of treatment with standard-dose PPI. ${ }^{15}$ Patients with severe EE (LA-C and LA-D) demonstrated an even higher PPI failure rate than those with less severe esophageal inflammation (LA-A and LA-B). In a study by Castell et $\mathrm{al}^{16}$ that included 1284 patients with $\mathrm{EE}$ who were randomized to once-daily lansoprazole $30 \mathrm{mg}$ or omeprazole $20 \mathrm{mg}$, revealed that $6.7 \%$ and $8.4 \%$, respectively, of those with LA-A or LA-B EE failed to heal after 8 weeks of treatment, compared with $11.3 \%$ and $14.7 \%$, respectively, of those with LA-C or LA-D. Richter et al ${ }^{17}$ demonstrated that the failure rate of patients with $\mathrm{EE}$ receiving either omeprazole $20 \mathrm{mg}$ or esomeprazole $40 \mathrm{mg}$ once daily was $9.6 \%$ and $6.6 \%$ for LA-A, $28.7 \%$ and $10.6 \%$ for LA-B, $29.6 \%$ and $12.8 \%$ for LA-C, and $26.2 \%$ and $20 \%$ for LA-D, respectively. Interestingly, a recent study found that the mean healing rate in EE was only $61.6 \%{ }^{8}$

Importantly, the rate of symptom resolution in $\mathrm{EE}$ patients receiving standard dose PPI was 10-15\% lower than the observed healing rate of esophageal inflammation. ${ }^{13,18}$ Consequently, patients with EE receiving standard dose PPIs may still suffer from heartburn or regurgitation despite a complete resolution of the esophageal inflammation. ${ }^{19}$ Moreover, even when continuing the initial healing dose as maintenance treatment for a period of 6 months, $15-23 \%$ of the patients with LA-A or LA-B, respectively, and $24-41 \%$ with LA-C or LA-D, respectively, relapsed while on treatment. ${ }^{20}$ Higuchi et al $^{8}$ showed that (after a mean 1.1 years of PPI therapy) approximately $40 \%$ of patients did not achieve remission of esophageal inflammation and that healing of esophageal inflammation was significantly lower $(42 \%)$ in patients with severe EE compared with patients having LA-A (71\%).

In summary, symptomatic response and healing rates of patients with severe EE have been relatively limited during PPI treatment. Thus, advanced grades of EE remain an area of unmet need for both symptomatic response and relapse of symptoms and esophageal inflammation.

\section{Nonerosive Reflux Disease}

The recognition of NERD as a distinct presentation of 
GERD is an important development in the field of GERD. While the definition of NERD has not changed significantly over the years, this disorder accounts for the majority of GERD patients seen in clinical practice. Overall, the results of recent epidemiological studies suggest that the prevalence of NERD in the GERD population is approximately $70 \%{ }^{2}$

NERD is one of the major areas of unmet need in the treatment of GERD and is related to less than optimal response to PPI therapy. In fact, NERD patients have a significantly lower symptomatic response rate (by 20-30\%) to PPI therapy as compared with patients having EE; consequently, NERD contributes the highest number of GERD patients to the refractory heartburn group. ${ }^{2,15}$ In a systematic review of the literature, PPI symptomatic response pooled rate was $36.7 \%$ in NERD patients and $55.5 \%$ in EE patients. ${ }^{21}$ The therapeutic gain was $27.5 \%$ in NERD compared with $48.9 \%$ in EE. A recent post hoc analysis of 4 randomized placebo-controlled trials demonstrated that partial heartburn response occurred in $20 \%$ of patients with NERD and $14 \%$ of those with $\mathrm{EE}^{22}$

In addition to the low symptomatic response rate, NERD patients also demonstrate a 2-3 fold increase in the lag time to symptomatic response to PPI therapy. By using the ReQuest ${ }^{\mathrm{TM}}$ questionnaire, the median time to first report of symptom relief was 2 days and 10-13 days to sustained symptom relief for NERD patients treated with either pantoprazole or esomeprazole (both 20 $\mathrm{mg} /$ day).

While many therapeutic trials of NERD patients did not exclude the functional heartburn group, it appears that even NERD patients with abnormal $\mathrm{pH}$ test demonstrate a lower symptomatic response rate to PPI once daily as compared with EE patients. ${ }^{23}$ Possible explanations include the important role of esophageal hypersensitivity (up to $87 \%$ in NERD patients) in NERD as compared with EE patients and the fact that the majority of NERD patients have mildly abnormal esophageal acid exposure. $^{23}$

In summary, the symptomatic response rate of NERD patients to standard dose PPI is significantly lower than that reported for EE patients. It is possible that esophageal hypersensitivity, which is not responsive to antireflux treatment, may drive this therapeutic discrepancy and thus create an important area of unmet need.

\section{Postprandial Heartburn}

Meal ingestion is the most common trigger for GERD-re- lated symptoms..$^{24,25}$ Postprandial heartburn drives millions of Americans to seek antireflux treatment on a daily basis. However, the currently available therapeutic modalities are not fast or effective enough to provide good control of postprandial heartburn. ${ }^{26-30}$

In patients who consume antireflux medications only in response to acute heartburn, PPIs appear to have no value due to the time required to reach maximum efficacy. Consequently, PPIs are not considered a good therapeutic option for postprandial heartburn, leaving patients to utilize compounds such as antacids, Gaviscon, sucralfate, or H2RAs. Furthermore, even in GERD patients who are taking PPIs on a regular basis, an especially large, fatty, spicy, or late -evening meal can result in breakthrough symptoms. Indeed, El-Serag et $\mathrm{al}^{31}$ found that high dietary fat intake was associated with an increased risk of GERD-related symptoms and EE, whereas high fiber intake correlated with a reduced risk of symptoms.

In summary, we are still devoid of effective antireflux therapeutic modalities for postprandial heartburn in patients who prefer to use them only when symptoms occur. Thus, postprandial heartburn remains an important area of unmet need.

\section{Nighttime Heartburn}

Nighttime heartburn is very common, affecting most patients with GERD. In a nationwide Gallup telephone survey of 1000 adults who were experiencing heartburn at least once a week, approximately $79 \%$ of respondents reported nocturnal heartburn. Of those, $75 \%$ reported that symptoms affected their sleep, and $40 \%$ reported problems in their ability to function the following day. ${ }^{32}$ Of those reporting nighttime heartburn, $71 \%$ were taking over-the-counter medications, but only $29 \%$ rated this approach as effective.

Another nationwide survey demonstrated that over $80 \%$ of adults taking PPIs for GERD reported nocturnal symptoms during the previous month, and $23.4 \%$ described their symptoms as severe or very severe. ${ }^{33}$ Almost $22 \%$ of responders were on PPI twice daily, and $42 \%$ supplemented the prescribed PPI with an over-the-counter PPI, H2RA, or antacid. ${ }^{33}$ Of those patients on PPI twice daily, almost $40 \%$ stated that they doubled the dose due to inadequate control of nighttime GERD-related symptoms. ${ }^{34}$ Several studies have also shown that the response rate of PPI once daily for nighttime heartburn is significantly lower (up to 53\%) than the response rate for daytime heartburn (up to 66\%). ${ }^{35,36}$

In summary, nighttime heartburn has the most important impact on the quality of life for GERD patients. However, night- 
time heartburn appears to be less responsive to antireflux treatment than daytime heartburn. Thus, nighttime heartburn remains one of the most important areas of unmet need.

\section{Maintenance Treatment of Erosive Esophagitis}

GERD is a chronic, relapsing disorder that requires longterm maintenance treatment for a substantial number of patients. This is particularly important for patients with EE. Once healing of mucosal erosions and symptom relief have been achieved by initial therapy, long-term maintenance treatment is necessary for most patients with EE (LA grades B-D). It has been demonstrated that, after discontinuation of maintenance treatment, relapse rates approach $90 \%$ in patients with $\mathrm{EE}$ and $75 \%$ in patients with NERD within 6 months after initial treatment. ${ }^{37}$ Moreover, even after initial healing of esophageal inflammation, symptomatic relapse occurs within the next 12 months in approximately $83.6 \%$ of patients with $\mathrm{EE}{ }^{13}$

More disconcerting is the high relapse rate of esophageal inflammation that patients with EE experience while on maintenance PPI treatment. Labenz et $\mathrm{al}^{38}$ have demonstrated a very high relapse rate of $\mathrm{EE}$ in patients taking the same PPI dose that initially healed their esophageal inflammation. Of those with LA-A and LA-B, $10 \%$ and $29 \%$, respectively, and those with LA-C and LA-D, $16 \%$ and $41 \%$, respectively, relapsed while on PPI once daily during 6 months of maintenance treatment. ${ }^{38}$ In this study, healing and remission rates among patients with LA-D at baseline were the lowest, regardless of the PPI dose or brand. ${ }^{38}$ In a community-based study by Carlsson et al, ${ }^{37}$ up to $25 \%$ of GERD patients continued to be symptomatic while on a standard dose of PPI. In patients with EE grade 3 based on Savary-Miller classification, $100 \%$ of those who were treated with H2RAs and $20 \%$ who were treated with a PPI experienced symptoms relapse within 12 months of initiating treatment. ${ }^{39}$

In summary, a substantial proportion of patients with EE, especially those with advanced grading (LA-C and LA-D) will relapse symptomatically, with or without mucosal inflammation, while on maintenance PPI treatment. This area of unmet need has become a major concern for both physicians and patients when long-term maintenance treatment for $\mathrm{EE}$ is required.

\section{On-demand/Intermittent Therapy}

Noncontinuous (on-demand or intermittent) PPI maintenance treatment strategies have been an area of intense interest for several decades. This is primarily due to studies showing that most patients with symptomatic GERD (60\%) are contented with on-demand or intermittent PPI therapy. ${ }^{40}$ On-demand therapy is a self-managed therapeutic strategy in which PPI intake is completely symptom driven, but patients are instructed not to take more than one PPI dose daily. ${ }^{41}$ Studies have shown that $50 \%$ of the patients who consume PPI daily become on-demand takers within one month. ${ }^{24}$ Thus, noncontinuous PPI treatment is preferred over continuous PPI treatment by many patients with GERD. In addition, because the risk of complications is minimal in patients with NERD or LA-A and LA-B EE, noncontinuous PPI treatment has become a very attractive therapeutic strategy. Furthermore, it may alleviate concerns of GERD patients about the potential for adverse events when chronic, daily PPI treatment is used.

Thus far, there are no approved indications for on-demand or intermittent therapy for any of the currently available PPIs in the United States. Consequently, noncontinuous PPI treatment remains an important area of unmet need in GERD.

\section{Refractory Gastroesophageal Reflux Disease}

Refractory GERD is defined as partial response or lack of response in GERD patients taking PPI twice daily over a period of at least 3 months. ${ }^{42}$ Others suggest that lack of symptomatic response to PPI once daily is sufficient to consider patients as having refractory GERD. ${ }^{43}$ Currently, this disorder is the most common presentation of GERD in gastroenterology practice. ${ }^{15}$ It has been estimated that between $10 \%$ and $40 \%$ of GERD patients fail to respond symptomatically, either partially or completely, to a standard-dose PPI. ${ }^{15}$

In a US survey that included 617 GERD patients taking PPIs, $71 \%$ used the PPI once a day, $22.2 \%$ twice a day, and $6.8 \%$ more than twice a day, or on an as-needed basis. ${ }^{44}$ Approximately $42.1 \%$ of all patients supplemented their prescription PPI with other antireflux regimens, including over-the-counter antacids and H2RAs. Although $72.8 \%$ of the patients were satisfied with their PPI treatment, 85\% still experienced GERD-related symptoms. ${ }^{44}$ An American Gastroenterological Association survey of patients with GERD revealed that $38 \%$ reported incomplete response to PPI treatment. ${ }^{45}$ Most of the non-responders supplemented their PPI therapy with other antireflux regimens, primarily over-the-counter antacids. In the 2000 Gallup 
Study of Consumers' Use of Stomach Relief Products, 36\% of responders reported taking nonprescription medication in addition to a prescription medication for GERD. ${ }^{24}$ Of those, $56 \%$ stated that they took their prescription medication daily but still needed to supplement it with nonprescription medication for breakthrough symptoms.

Most non-responders to PPIs are NERD and functional heartburn patients because of the relatively large size of each of these groups among those who suffer from heartburn. ${ }^{46}$ Importantly, the pooled symptomatic response rate to PPIs once daily at 4 weeks was only $37 \%$ for patients with NERD compared with $56 \%$ for patients with EE. ${ }^{21}$ Various mechanisms have been proposed to contribute to PPI failure: these include poor compliance or adherence to PPI treatment, residual acid reflux, weakly acidic and weakly alkaline reflux, bile reflux, esophageal hypersensitivity, comorbidities (functional bowel disorders and gastroparesis), and psychological comorbidity among others. ${ }^{46}$

Treatment of refractory GERD remains an area of unmet need regardless of the underlying cause. Thus far, attempts to develop novel therapies that could be helpful in refractory GERD have been disappointing. The transient lower esophageal sphincter relaxation reducers, which were specifically developed to address residual acid reflux, bile reflux, or non-acid reflux, represented a promising class of drugs that failed to demonstrate efficacy in large clinical trials of patients with refractory GERD. ${ }^{47}$

\section{Atypical Manifestations of Gastroesophageal Reflux Disease}

NCCP is defined as recurrent chest pain that is indistinguishable from ischemic heart pain after a reasonable workup has excluded a cardiac cause. ${ }^{48} \mathrm{NCCP}$ is highly prevalent. Chest pain is currently the second most common presentation to hospital emergency departments; however, only $25 \%$ of people who experience chest pain actually present to a hospital. ${ }^{49}$ The mean annual prevalence of NCCP in 6 population-based studies was approximately $25 \% .^{50}$ In one population-based US survey, the prevalence of NCCP among GERD patients was $23 \%$ without a gender predilection. ${ }^{7}$ An Australian epidemiological study demonstrated a prevalence rate of $33 \%^{51,52}$ as well as a reduction in population prevalence with increasing age. Similar prevalence rates of $23 \%$ and $19 \%$ were reported by epidemiological studies from South America and China, respectively. ${ }^{53,54}$

GERD is the most important esophageal cause of NCCP. In a community-based study, 53\% of all NCCP patients experi- enced heartburn and 58\% acid regurgitation. ${ }^{52}$ Furthermore, Locke et $\mathrm{al}^{7}$ have demonstrated that NCCP was more commonly reported by patients $(37 \%)$ who experienced heartburn symptoms at least weekly as compared with $30.7 \%$ of those who had infrequent heartburn (less than once a week) and $7.9 \%$ of those without any GERD symptoms. Ambulatory 24-hour esophageal $\mathrm{pH}$ testing studies have demonstrated that approximately $50 \%$ of NCCP patients have abnormal esophageal acid exposure.

Studies have demonstrated that the symptom response rate to short-course PPI treatment in NCCP patients with objective evidence of GERD (esophagitis and/or abnormal pH test) is between $78 \%$ and $92 \% .^{55,56}$ Conversely, response to PPI treatment in NCCP patients without objective evidence of GERD ranged between $10 \%$ and $14 \% .{ }^{56-58}$ However, there are less than a handful of randomized, placebo-controlled trials that evaluated the value of PPI treatment in GERD-related NCCP. ${ }^{59,60}$ The results of these studies have not been consistent, and thus far the value of antireflux treatment in GERD-related $\mathrm{NCCP}$ remains to be elucidated.

Presently, none of the antireflux medications is specifically indicated for GERD-related NCCP; consequently, GERD-related NCCP remains an important area of unmet need.

\section{Extraesophageal Manifestations of Gastroesophageal Reflux Disease}

Surprisingly, despite decades of research in the area of extraesophageal manifestations of GERD, we are still lacking an effective therapeutic strategy, and none of the currently available antireflux medications is indicated for any of them.

The extraesophageal manifestations of GERD include, among others, asthma, chronic cough, hoarseness, dental erosions, and sleep disorders. Early population-based studies suggested that GERD patients are at an increased risk of developing ear, nose, and throat or pulmonary symptoms. ${ }^{61}$ The ProGERD study (6000 patients with EE and NERD) found that approximately $30 \%$ of the patients reported extraesophageal manifestations of GERD including 385 (13.3\%), 307 (10.6\%), and 131 $(4.5 \%)$ patients who demonstrated chronic cough, laryngeal disorders, and asthma, respectively. ${ }^{62}$

Furthermore, most randomized control trials using PPIs in patients with pharyngeal, laryngeal, or pulmonary symptoms (presumed to be GERD related) demonstrated poor response or very modest benefit at best. Moreover, there is no accepted test to establish the diagnosis of extraesophageal manifestations. Thus, 
while association between extraesophageal manifestations and GERD has been commonly reported, a causal relationship remains to be substantiated. ${ }^{63}$

In the adult population, GERD is the third most common cause of chronic cough after postnasal drip and asthma. ${ }^{64}$ In a US population-based study, the frequency of chronic cough in patients with no GERD symptoms, infrequent GERD symptoms, and frequent GERD symptoms was $11 \%, 15 \%$, and $22 \%$, respectively. ${ }^{7}$ Irwin et $\mathrm{al}^{65}$ showed that GERD may serve as the leading etiology in $10 \%$ of patients with chronic cough.

Patients with chronic cough that is presumed to be GERD related are currently treated by twice-daily PPI for a period of 3 months. However, this therapeutic strategy is supported only by open-label trials and not by randomized placebo-controlled studies. Baldi et $\mathrm{al}^{66}$ found no significant difference in symptom improvement for patients with chronic cough who were treated with $30 \mathrm{mg}$ lansoprazole, either once a day or twice a day, over a period of 12 weeks. Two recent, double-blind, placebo-controlled trials in adult patients with chronic cough did not demonstrate that PPIs are more effective than placebo. ${ }^{67,68} \mathrm{~A}$ recent metaanalysis of 5 randomized, placebo-controlled trials in adult patients with chronic cough did not find sufficient evidence in favor of PPI therapy. ${ }^{69}$

Hoarseness has also been considered to be an important extraesophageal manifestation of GERD. In a US populationbased study, the frequency of hoarseness in patients with weekly GERD symptoms was $23 \%$ compared with $11 \%$ for those without GERD symptoms. ${ }^{7}$ Typical GERD-related symptoms (heartburn and regurgitation) are absent in the majority of patients with chronic laryngitis, and the presence of esophageal inflammation ranges from $19 \%$ to $40 \%$ in these patients. ${ }^{70,71}$ Abnormal esophageal $\mathrm{pH}$ monitoring was found in 55-79\% and $18-70 \%$ of patients with chronic hoarseness or posterior laryngitis, respectively. ${ }^{71-74}$

Studies have shown that PPI therapy is not more beneficial than placebo for the treatment of hoarseness and other laryngeal manifestations in patients with documented posterior laryngitis. In a large randomized, placebo-controlled, multicenter trial of 145 patients, Vaezi et $\mathrm{al}^{75}$ were unable to demonstrate that $40 \mathrm{mg}$ esomeprazole twice daily for 16 weeks was better than placebo for symptom resolution or improvement in laryngeal signs of laryngopharyngeal reflux. A subsequent meta-analysis of the placebo-controlled studies in laryngopharyngeal reflux has reported minimal therapeutic benefit of PPIs over placebo. ${ }^{76}$

GERD has also been shown to be present in $50-80 \%$ of asth- matic patients. ${ }^{77,78}$ Reports of GERD-related symptoms in adults with asthma range from $65 \%$ to $77 \% .{ }^{61,79-81}$ In a large case-controlled study, El-Serag et $\mathrm{al}^{61}$ reported that $\mathrm{EE}$ and esophageal stricture were associated with chronic bronchitis, asthma, chronic obstructive pulmonary disease, pulmonary fibrosis, bronchiectasis, and pneumonia, with odds ratios ranging from 1.15 to 1.50 . In a recent 5-year follow-up of the original ProGERD study, the prevalence of asthma in GERD patients had increased from $4.5 \%$ at entry to $7.8 \%$ at the end of follow-up. ${ }^{82}$ Kiljander et $\mathrm{al}^{83}$ showed that $35 \%$ of asthma patients had abnormal 24-hour esophageal $\mathrm{pH}$ monitoring.

Response to PPI therapy in asthmatics remains to be fully elucidated. In a systematic review of all clinical trials using medical therapy in asthmatic patients with GERD (between the years 1966 and 1996) it was found that antireflux treatment improved asthma symptoms, reduced consumption of asthma-related medications, and improved evening peak expiratory flow in 69\%,62\%, and $26 \%$ of subjects, respectively. ${ }^{84}$ In a placebo-controlled study, it was found that esomeprazole $40 \mathrm{mg}$ twice daily, given for 4 months, improved peak expiratory flow in $45.4 \%$ of subjects with asthma who presented with both GERD and nocturnal respiratory symptoms. ${ }^{85}$ Conversely, a recent study of 412 patients with poorly controlled asthma, conducted by the American Lung Association Asthma Clinical Research Center, did not find any benefit for either esomeprazole $40 \mathrm{mg}$ twice daily or placebo after 24 weeks of treatment. ${ }^{86}$ Similarly, a Cochrane Review of antireflux therapy in patients with asthma found only minimal improvement of asthma symptoms with therapy. ${ }^{87}$

Overall, extraesophageal manifestations of GERD clearly represent an area of unmet need in GERD. Further understanding of the mechanistic relationship between GERD and their symptoms will help to find better therapeutic modalities.

\section{Dependency on Food for Efficacy}

Proper timing of PPI administration is needed for maximum efficacy. Thus, a PPI should be taken 30 minutes before a meal (preferably before breakfast). However, more than $50 \%$ of GERD patients do not adhere to proper timing of PPI consumption when prescribed by a primary care physician. ${ }^{88}$

Gunaratnam et $\mathrm{al}^{89}$ showed that only $46 \%$ of refractory GERD patients were dosing their PPI optimally. Of those who dosed suboptimally, 39\% took their PPI at bedtime, and $4 \%$ took it as needed. In a 2000 Gallup survey, consumption of antireflux medications prior to going to bed was reported by $52 \%$ of 
subjects. ${ }^{24}$ Furthermore, in a US survey involving almost 500 physicians demonstrated that $70 \%$ of primary care physicians and $20 \%$ of gastroenterologists advised patients to take their PPI at bedtime or did not believe that proper timing of drug administration was important. ${ }^{90}$

In summary, a more flexible schedule that obviates the need for proper timing recommendations may improve compliance as well as clinical efficacy of PPIs.

\section{Long-term or High-dose Proton Pump Inhibitor Therapy}

There has recently been growing evidence of adverse effects related to chronic PPI treatment. ${ }^{91}$ These include increased risk of hip, wrist, and spine fracture; community-acquired pneumonia; Clostridium difficile colitis; microscopic colitis; bacterial overgrowth; vitamin/mineral/electrolyte deficiencies; and fundic gland polyps. ${ }^{92-97}$ While the risk for most of these complications is relatively modest, concerns have been raised about the safety of long-term PPI therapies.

Duration and dosing of PPI treatment have been shown to increase the risk for developing the aforementioned adverse events. ${ }^{91}$ Importantly, it has been estimated that nearly $30 \%$ of GERD patients are treated with a double-dose PPI. ${ }^{44}$

A growing concern by patients and physicians alike provided the impetus for identifying alternative efficacious therapeutic options (medical, endoscopic, or surgical) for GERD patients who require long-term and/or high-dose PPI treatment (Table 2).

Table 2. Currently Available Alternative Therapeutic Options for Chronic or High-dose Proton Pupm Inhibitor Treatment

\begin{tabular}{cl}
\hline \multicolumn{1}{c}{ Medical $^{\mathrm{a}}$} & \multicolumn{1}{c}{ Non-medical } \\
\hline - Antacids/ & - Compliance/adherence to PPI \\
Gaviscon & - Lifestyle modifications \\
- Sucralfate & - Complementary/alternative medicine \\
- H2RAs & - Psychological intervention \\
- Prokinetics & Endoscopic: \\
- Baclofen & - Stretta procedure \\
& - EsophyX Transoral incisionless fundoplication \\
& - Medigus Ultrasonic Surgical Endostapler \\
& Surgical: \\
& - Surgical fundoplication \\
& - Magnetic sphincter augmentation device (LINX)
\end{tabular}

${ }^{a}$ Use separately or as an add-on to proton pump inhibitor (PPI) treatment. H2RAs, histamine 2 receptor antagonists.

\section{Barrett's Esophagus}

$\mathrm{BE}$ is considered a complication of chronic GERD. ${ }^{98,99}$ The prevalence of specialized intestinal metaplasia in patients with GERD is between $6 \%$ and $12 \%$, and the adjusted odds ratio for developing adenocarcinoma over a 20 -year period is 7.7 and 43.5 for patients with recurrent and severe symptoms of GERD, respectively. ${ }^{98}$ As a group, patients with $\mathrm{BE}$ have demonstrated the highest level of acid exposure in the distal esophagus compared with those having NERD or EE, suggesting the need for more aggressive antireflux treatment. ${ }^{100}$

However, there is a discrepancy in BE between symptom resolution and control of intraesophageal acid exposure. ${ }^{101}$ Studies with ambulatory 24-hour esophageal $\mathrm{pH}$ monitoring revealed that $20-80 \%$ of symptomatically controlled BE patients continued to demonstrate some level of abnormal acid exposure, suggesting that these patients may be undertreated. ${ }^{102,103}$ Interestingly this phenomenon has been described even when high doses of PPI (up to 4 times daily) have been used. ${ }^{104}$

Thus far, none of the currently available PPIs is indicated for patients with BE. Large randomized, placebo-controlled trials are also needed to assess the value of antireflux treatment for controlling the symptoms of $\mathrm{BE}$ patients. This is in addition to the evaluation of chronic PPI treatment post-BE ablation.

\section{Bariatric Surgery}

In recent years, bariatric surgery has become one of the mainstay treatments for weight loss among obese patients. ${ }^{105}$ Presently, the most commonly performed bariatric surgeries are laparoscopic adjustable gastric banding, Roux en-Y gastric bypass, and laparoscopic sleeve gastrectomy. ${ }^{106}$ However, there have been growing concerns about side effects induced by these surgical techniques, including stenosis at the anastomosis site, stomal ulcer, fistula, band erosion, and motor dysfunction of the esophagus, stomach, and small bowel among others. ${ }^{107-111}$

Thus far, only a few studies have assessed the objective presence of GERD prior to bariatric surgery, most specifically in patients undergoing laparoscopic sleeve gastrectomy or adjustable gastric banding. There is a lack of uniformity in assessing the presence of GERD pre-and post-bariatric surgery, using validated GERD-questionnaires, ambulatory $\mathrm{pH}$ monitoring, or upper endoscopy.

GERD occurs in up to $70 \%$ of obese patients. Most im- 
portantly, several studies have reported that bariatric surgery might exacerbate or induce new onset GERD-related symptoms in asymptomatic patients undergoing laparoscopic adjustable gastric banding ${ }^{112-114}$ or laparoscopic sleeve gastrectomy. ${ }^{15-117}$ Furthermore, Dupree et al ${ }^{115}$ reported that up to $9 \%$ of patients undergoing sleeve gastrectomy presented with new-onset GERD postoperatively and that approximately $84 \%$ continued to have GERD symptoms after the surgery. Moreover, the presence of GERD has been shown to increase the risk of postoperative complications in $15 \%$ of the patients. ${ }^{115}$ Importantly, patients with GERD post bariatric surgery appear to be more resistant to antireflux treatment and thus serve as an important area of unmet need.

\section{References}

1. Peery AF, Dellon ES, Lund J, et al. Burden of gastrointestinal disease in the United States: 2012 update. Gastroenterology 2012;143: 1179-1187, e1-e3.

2. Hershcovici T, Fass R. Nonerosive reflux disease (NERD) - An Update. J Neurogastroenterol Motil 2010;16:8-21.

3. Dekel R, Morse C, Fass R. The role of proton pump inhibitors in gastro-oesophageal reflux disease. Drugs 2004;64:277-295.

4. Coron E, Hatlebakk JG, Galmiche JP. Medical therapy of gastroesophageal reflux disease. Curr Opin Gastroenterol 2007;23:434439.

5. Lundell LR, Dent J, Bennett JR, et al. Endoscopic assessment of oesophagitis: clinical and functional correlates and further validation of the Los Angeles classification. Gut 1999;45:172-180.

6. Dent J, El-Serag HB, Wallander MA, Johansson S. Epidemiology of gastro-oesophageal reflux disease: a systematic review. Gut 2005;54:710-717.

7. Locke GR 3rd, Talley NJ, Fett SL, Zinsmeister AR, Melton LJ 3rd. Prevalence and clinical spectrum of gastroesophageal reflux: a population-based study in Olmsted County, Minnesota. Gastroenterology 1997;112:1448-1456.

8. Higuchi K, Joh T, Nakada K, Haruma K. Is proton pump inhibitor therapy for reflux esophagitis sufficient?: a large real-world survey of Japanese patients. Intern Med 2013;52:1447-1454.

9. Kim N, Lee SW, Cho SI, et al. The prevalence of and risk factors for erosive oesophagitis and non-erosive reflux disease: a nationwide multicentre prospective study in Korea. Aliment Pharmacol Ther 2008;27:173-185.

10. Johnson DA, Fennerty MB. Heartburn severity underestimates erosive esophagitis severity in elderly patients with gastroesophageal reflux disease. Gastroenterology 2004;126:660-664.

11. Chang CS, Poon SK, Lien HC, Chen GH. The incidence of reflux esophagitis among the Chinese. Am J Gastroenterol 1997;92:668671.

12. Loof L, Götell P, Elfberg B. The incidence of reflux oesophagitis. A study of endoscopy reports from a defined catchment area in Sweden. Scand J Gastroenterol 1993;28:113-118.
13. Chiba N, De Gara CJ, Wilkinson JM, Hunt RH. Speed of healing and symptom relief in grade II to IV gastroesophageal reflux disease: a meta-analysis. Gastroenterology 1997;112:1798-1810.

14. Lien HC, Chang CS, Yeh HZ, et al. Increasing prevalence of erosive esophagitis among Taiwanese aged 40 years and above: a comparison between two time periods. J Clin Gastroenterol 2009;43: 926-932.

15. Fass R, Sifrim D. Management of heartburn not responding to proton pump inhibitors. Gut 2009;58:295-309.

16. Castell DO, Richter JE, Robinson M, Sontag SJ, Haber MM. Efficacy and safety of lansoprazole in the treatment of erosive reflux esophagitis. The Lansoprazole Group. Am J Gastroenterol 1996; 91:1749-1757.

17. Richter JE, Kahrilas PJ, Johanson J, et al. Efficacy and safety of esomeprazole compared with omeprazole in GERD patients with erosive esophagitis: a randomized controlled trial. Am J Gastroenterol 2001;96:656-665.

18. Sharma VK, Leontiadis GI, Howden CW. Meta-analysis of randomized controlled trials comparing standard clinical doses of omeprazole and lansoprazole in erosive oesophagitis. Aliment Pharmacol Ther 2001;15:227-231.

19. Fass R. Healing erosive esophagitis with a proton pump inhibitor: the more the merrier? Am J Gastroenterol 2012;107:531-533.

20. Hershcovici T, Fass R. Pharmacological management of GERD: where does it stand now? Trends Pharmacol Sci 2011;32:258-264.

21. Dean BB, Gano AD Jr, Knight K, Ofman JJ, Fass R. Effectiveness of proton pump inhibitors in nonerosive reflux disease. Clin Gastroenterol Hepatol 2004;2:656-664.

22. Bytzer P, van Zanten SV, Mattsson H, Wernersson B. Partial symptom-response to proton pump inhibitors in patients with non-erosive reflux disease or reflux oesophagitis - a post hoc analysis of 5796 patients. Aliment Pharmacol Ther 2012;36:635-643.

23. Lind T, Havelund T, Carlsson R, et al. Heartburn without oesophagitis: efficacy of omeprazole therapy and features determining therapeutic response. Scand J Gastroenterol 1997;32:974-979.

24. Gallup Organization. The 2000 Gallup study of consumers' use of stomach relief products. Princeton: Gallup Organization 2000.

25. Dent J. Gastro-oesophageal reflux disease. Digestion 1998;59:433445.

26. Boeckxstaens GE, Hirsch DP, Fakhry N, Holloway RH, D'Amato $\mathrm{M}$, Tytgat GN. Involvement of cholecystokininA receptors in transient lower esophageal sphincter relaxations triggered by gastric distension. Am J Gastroenterol 1998;93:1823-1828.

27. van Wijk MP, Blackshaw LA, Dent J, Benninga MA, Davidson GP, Omari TI. Distension of the esophagogastric junction augments triggering of transient lower esophageal sphincter relaxation. Am J Physiol Gastrointest Liver Physiol 2011;301:G713-G718.

28. Pauwels A, Altan E, Tack J. The gastric accommodation response to meal intake determines the occurrence of transient lower esophageal sphincter relaxations and reflux events in patients with gastro-esophageal reflux disease. Neurogastroenterol Motil 2014;26: 581-588.

29. Holloway RH, Kocyan P, Dent J. Provocation of transient lower esophageal sphincter relaxations by meals in patients with symptomatic gastroesophageal reflux. Dig Dis Sci 1991;36:1034-1039.

30. Robinson M, Rodriguez-Stanley S, Ciociola AA, et al. Synergy be- 
tween low-dose ranitidine and antacid in decreasing gastric and oesophageal acidity and relieving meal-induced heartburn. Aliment Pharmacol Ther 2001;15:1365-1374.

31. El-Serag HB, Satia JA, Rabeneck L. Dietary intake and the risk of gastro-oesophageal reflux disease: a cross sectional study in volunteers. Gut 2005;54:11-17.

32. Shaker R, Castell DO, Schoenfeld PS, Spechler SJ. Nighttime heartburn is an under-appreciated clinical problem that impacts sleep and daytime function: the results of a Gallup survey conducted on behalf of the American Gastroenterological Association. Am J Gastroenterol 2003;98:1487-1493.

33. Chey WD, MR, Chen L, et al. Nighttime symptoms and sleep impairment among patients with gastro-esophageal reflux disease (GERD) receiving prescription (Rx) proton pump inhibitors (PPIs). Gastroenterology 2008;134(suppl 1):A323-A324.

34. Chey WD, MR, Kothari S, et al. Are proton pump inhibitors (PPIs) sufficient in controlling symptoms of gastro-esophageal reflux disease (GERD)?: a community-based US survey study. Gastroenterology 2008;134(suppl 1):A325.

35. Johnson DA, Orr WC, Crawley JA, et al. Effect of esomeprazole on nighttime heartburn and sleep quality in patients with GERD: a randomized, placebo-controlled trial. Am J Gastroenterol 2005; 100:1914-1922.

36. Richter JE, Kahrilas PJ, Sontag SJ, Kovacs TO, Huang B, Pencyla $\mathrm{JL}$. Comparing lansoprazole and omeprazole in onset of heartburn relief: results of a randomized, controlled trial in erosive esophagitis patients. Am J Gastroenterol 2001;96:3089-3098.

37. Carlsson R, Dent J, Watts R, et al. Gastro-oesophageal reflux disease in primary care: an international study of different treatment strategies with omeprazole. International GORD Study Group. Eur J Gastroenterol Hepatol 1998;10:119-124.

38. Labenz J, Armstrong D, Lauritsen K, et al. Esomeprazole $20 \mathrm{mg}$ vs. pantoprazole $20 \mathrm{mg}$ for maintenance therapy of healed erosive oesophagitis: results from the EXPO study. Aliment Pharmacol Ther 2005;22:803-811.

39. Vigneri S, Termini R, Leandro G, et al. A comparison of five maintenance therapies for reflux esophagitis. N Engl J Med 1995;333: 1106-1110.

40. Bardhan KD, Müller-Lissner S, Bigard MA, et al. Symptomatic gastro-oesophageal reflux disease: double blind controlled study of intermittent treatment with omeprazole or ranitidine. The European Study Group. BMJ 1999;318:502-507.

41. Peghini PL, Katz PO, Castell DO. Ranitidine controls nocturnal gastric acid breakthrough on omeprazole: a controlled study in normal subjects. Gastroenterology 1998;115:1335-1339.

42. Sifrim D, Zerbib F. Diagnosis and management of patients with reflux symptoms refractory to proton pump inhibitors. Gut 2012;61: 1340-1354.

43. Hershcovici T, Fass R. An algorithm for diagnosis and treatment of refractory GERD. Best Pract Res Clin Gastroenterol 2010;24: 923-936.

44. Chey WD, Mody RR, Wu EQ, et al. Treatment patterns and symptom control in patients with GERD: US community-based survey. Curr Med Res Opin 2009;25:1869-1878.

45. Hershcovici T, Fass R. Management of gastroesophageal reflux disease that does not respond well to proton pump inhibitors. Curr
Opin Gastroenterol 2010;26:367-378.

46. Hershcovici T, Fass R. Step-by-step management of refractory gastresophageal reflux disease. Dis Esophagus 2013;26:27-36.

47. Hershcovici T, Mashimo H, Fass R. The lower esophageal sphincter. Neurogastroenterol Motil 2011;23:819-830.

48. Fass R, Achem SR. Noncardiac chest pain: epidemiology, natural course and pathogenesis. J Neurogastroenterol Motil 2011;17:110123.

49. Potokar JP, Nutt DJ. Chest pain: panic attack or heart attack? Int J Clin Pract 2000;54:110-114.

50. Ducrotté P, Liker HR. How do people with gastro-oesophageal reflux disease perceive their disease? Results of a multinational survey. Curr Med Res Opin 2007;23:2857-2865.

51. Eslick GD. Noncardiac chest pain: epidemiology, natural history, health care seeking, and quality of life. Gastroenterol Clin North Am 2004;33:1-23.

52. Eslick GD, Jones MP, Talley NJ. Non-cardiac chest pain: prevalence, risk factors, impact and consulting--a population-based study. Aliment Pharmacol Ther 2003;17:1115-1124.

53. Chiocca JC, Olmos JA, Salis GB, et al. Prevalence, clinical spectrum and atypical symptoms of gastro-oesophageal reflux in Argentina: a nationwide population-based study. Aliment Pharmacol Ther 2005; 22:331-342

54. Wong WM, Lai KC, Lam KF, et al. Prevalence, clinical spectrum and health care utilization of gastro-oesophageal reflux disease in a Chinese population: a population-based study. Aliment Pharmacol Ther 2003;18:595-604.

55. Fass R, Fennerty MB, Ofman JJ, et al. The clinical and economic value of a short course of omeprazole in patients with noncardiac chest pain. Gastroenterology 1998;115:42-49.

56. Bautista J, Fullerton H, Briseno M, Cui H, Fass R. The effect of an empirical trial of high-dose lansoprazole on symptom response of patients with non-cardiac chest pain--a randomized, double-blind, placebo-controlled, crossover trial. Aliment Pharmacol Ther 2004; 19:1123-1130.

57. Dickman R, Emmons S, Cui H, et al. The effect of a therapeutic trial of high-dose rabeprazole on symptom response of patients with non-cardiac chest pain: a randomized, double-blind, placebo-controlled, crossover trial. Aliment Pharmacol Ther 2005;22:547-555.

58. Dickman R, Mattek N, Holub J, Peters D, Fass R. Prevalence of upper gastrointestinal tract findings in patients with noncardiac chest pain versus those with gastroesophageal reflux disease (GERD)related symptoms: results from a national endoscopic database. Am J Gastroenterol 2007;102:1173-1179.

59. Achem SR, Kolts BE, MacMath T, et al. Effects of omeprazole versus placebo in treatment of noncardiac chest pain and gastroesophageal reflux. Dig Dis Sci 1997;42:2138-2145.

60. Flook NW, Moayyedi P, Dent J, et al. Acid-suppressive therapy with esomeprazole for relief of unexplained chest pain in primary care: a randomized, double-blind, placebo-controlled trial. Am J Gastroenterol 2013;108:56-64.

61. El-Serag HB, Sonnenberg A. Comorbid occurrence of laryngeal or pulmonary disease with esophagitis in United States military veterans. Gastroenterology 1997;113:755-760.

62. Jaspersen D, Kulig M, Labenz J, et al. Prevalence of extra-oesophageal manifestations in gastro-oesophageal reflux disease: an anal- 
ysis based on the ProGERD Study. Aliment Pharmacol Ther 2003;17:1515-1520.

63. Wong WM, Fass R. Extraesophageal and atypical manifestations of GERD. J Gastroenterol Hepatol 2004;19(suppl 3):S33-S43.

64. Irwin RS, Boulet LP, Cloutier MM, et al. Managing cough as a defense mechanism and as a symptom. A consensus panel report of the American College of Chest Physicians. Chest 1998;114(suppl): 133S-181S.

65. Irwin RS, Corrao WM, Pratter MR. Chronic persistent cough in the adult: the spectrum and frequency of causes and successful outcome of specific therapy. Am Rev Respir Dis 1981;123(4 Pt 1): 413-417.

66. Baldi F, Cappiello R, Cavoli C, Ghersi S, Torresan F, Roda E. Proton pump inhibitor treatment of patients with gastroesophageal reflux-related chronic cough: a comparison between two different daily doses of lansoprazole. World J Gastroenterol 2006;12:82-88.

67. Shaheen NJ, Crockett SD, Bright SD, et al. Randomised clinical trial: high-dose acid suppression for chronic cough - a double-blind, placebo-controlled study. Aliment Pharmacol Ther 2011;33:225234.

68. Faruqi S, Molyneux ID, Fathi H, Wright C, Thompson R, Morice AH. Chronic cough and esomeprazole: a double-blind placebo-controlled parallel study. Respirology 2011;16:1150-1156.

69. Chang AB, Lasserson TJ, Gaffney J, Connor FL, Garske LA. Gastro-oesophageal reflux treatment for prolonged non-specific cough in children and adults. Cochrane Database Syst Rev 2005;(2):CD004823.

70. Kamel PL, Hanson D, Kahrilas PJ. Omeprazole for the treatment of posterior laryngitis. Am J Med 1994;96:321-326.

71. Havas T, Huang S, Levy M. Posterior pharyngolaryngitis. Double-blind randomized placebo-controlled trial of proton pump inhibitor therapy. Aust J Otolaryngol 1999;3:243-246.

72. Katz PO. Ambulatory esophageal and hypopharyngeal $\mathrm{pH}$ monitoring in patients with hoarseness. Am J Gastroenterol 1990;85:3840 .

73. Jacob P, Kahrilas PJ, Herzon G. Proximal esophageal pH-metry in patients with 'reflux laryngitis'. Gastroenterology 1991;100:305-310.

74. Shaker R, Milbrath M, Ren J, et al. Esophagopharyngeal distribution of refluxed gastric acid in patients with reflux laryngitis. Gastroenterology 1995;109:1575-1582.

75. Vaezi MF, Richter JE, Stasney CR, et al. Treatment of chronic posterior laryngitis with esomeprazole. Laryngoscope 2006;116:254-260.

76. Qadeer MA, Phillips CO, Lopez AR, et al. Proton pump inhibitor therapy for suspected GERD-related chronic laryngitis: a metaanalysis of randomized controlled trials. Am J Gastroenterol 2006; 101:2646-2654.

77. Mays EE. Intrinsic asthma in adults. Association with gastroesophageal reflux. JAMA 1976;236:2626-2628.

78. Sontag SJ. The spectrum of pulmonary symptoms due to gastroesophageal reflux. Thorac Surg Clin 2005;15:353-368.

79. Perrin-Fayolle M, Bel A, Kofman J, et al. [Asthma and gastro-esophageal reflux. Results of a survey over 150 cases (author's transl)]. Poumon Coeur 1980;36:225-230. [French]

80. Sontag SJ, O'Connell S, Khandelwal S, et al. Most asthmatics have gastroesophageal reflux with or without bronchodilator therapy. Gastroenterology 1990;99:613-620.
81. Field SK, Underwood M, Brant R, Cowie RL. Prevalence of gastroesophageal reflux symptoms in asthma. Chest 1996;109:316-322.

82. Jaspersen D, Nocon M, Labenz J, et al. Clinical course of laryngo-respiratory symptoms in gastro-oesophageal reflux disease during routine care--a 5-year follow-up. Aliment Pharmacol Ther 2009;29:1172-1178.

83. Kiljander TO, Salomaa ER, Hietanen EK, Terho EO. Gastroesophageal reflux in asthmatics: a double-blind, placebo-controlled crossover study with omeprazole. Chest 1999;116:1257-1264.

84. Field SK, Sutherland LR. Does medical antireflux therapy improve asthma in asthmatics with gastroesophageal reflux?: a critical review of the literature. Chest 1998;114:275-283.

85. Kiljander TO, Harding SM, Field SK, et al. Effects of esomeprazole $40 \mathrm{mg}$ twice daily on asthma: a randomized placebo-controlled trial. Am J Respir Crit Care Med 2006;173:1091-1097.

86. American Lung Association Asthma Clinical Research Centers, Mastronarde JG, Anthonisen NR, et al. Efficacy of esomeprazole for treatment of poorly controlled asthma. N Engl J Med 2009; 360:1487-1499.

87. Gibson PG, Powell H, Coughlan J, et al. Limited (information only) patient education programs for adults with asthma. Cochrane Database Syst Rev 2002;(2):CD001005.

88. Sheikh I, Waghray A, Waghray N, Dong C, Wolfe MM. Consumer use of over-the-counter proton pump inhibitors in patients with gastroesophageal reflux disease. Am J Gastroenterol 2014;109:789-794.

89. Gunaratnam NT, Jessup TP, Inadomi J, Lascewski DP. Sub-optimal proton pump inhibitor dosing is prevalent in patients with poorly controlled gastro-oesophageal reflux disease. Aliment Pharmacol Ther 2006;23:1473-1477.

90. Barrison AF, Jarboe LA, Weinberg BM, Nimmagadda K, Sullivan LM, Wolfe MM. Patterns of proton pump inhibitor use in clinical practice. Am J Med 2001;111:469-473.

91. Fass R. Alternative therapeutic approaches to chronic proton pump inhibitor treatment. Clin Gastroenterol Hepatol 2012;10:338-345.

92. Yang YX, Metz DC. Safety of proton pump inhibitor exposure. Gastroenterology 2010;139:1115-1127.

93. Keszthelyi D, Jansen SV, Schouten GA, et al. Proton pump inhibitor use is associated with an increased risk for microscopic colitis: a case-control study. Aliment Pharmacol Ther 2010;32:1124-1128.

94. Lombardo L, Foti M, Ruggia O, Chiecchio A. Increased incidence of small intestinal bacterial overgrowth during proton pump inhibitor therapy. Clin Gastroenterol Hepatol 2010;8:504-508.

95. McColl KE. Effect of proton pump inhibitors on vitamins and iron. Am J Gastroenterol 2009;104(suppl 2):S5-S9.

96. Dial S, Alrasadi K, Manoukian C, Huang A, Menzies D. Risk of Clostridium difficile diarrhea among hospital inpatients prescribed proton pump inhibitors: cohort and case-control studies. CMAJ 2004;171:33-38.

97. Laheij RJ, Sturkenboom MC, Hassing RJ, Dieleman J, Stricker $\mathrm{BH}$, Jansen JB. Risk of community-acquired pneumonia and use of gastric acid-suppressive drugs. JAMA 2004;292:1955-1960.

98. Lagergren J, Bergström R, Lindgren A, Nyrén O. Symptomatic gastroesophageal reflux as a risk factor for esophageal adenocarcinoma. N Engl J Med 1999;340:825-831.

99. Sampliner RE. Practice guidelines on the diagnosis, surveillance, 
and therapy of Barrett's esophagus. The Practice Parameters Committee of the American College of Gastroenterology. Am J Gastroenterol 1998;93:1028-1032.

100. Martinez SD, Malagon IB, Garewal HS, Cui H, Fass R. Non-erosive reflux disease (NERD)--acid reflux and symptom patterns. Aliment Pharmacol Ther 2003;17:537-545.

101. Fass R, Shapiro M, Dekel R, Sewell J. Systematic review: proton-pump inhibitor failure in gastro-oesophageal reflux disease--where next? Aliment Pharmacol Ther 2005;22:79-94.

102. Katzka DA, Castell DO. Successful elimination of reflux symptoms does not insure adequate control of acid reflux in patients with Barrett's esophagus. Am J Gastroenterol 1994;89:989-991.

103. Ouatu-Lascar R, Triadafilopoulos G. Complete elimination of reflux symptoms does not guarantee normalization of intraesophageal acid reflux in patients with Barrett's esophagus. Am J Gastroenterol 1998;93:711-716.

104. Fass R, Sampliner RE, Malagon IB, et al. Failure of oesophageal acid control in candidates for Barrett's oesophagus reversal on a very high dose of proton pump inhibitor. Aliment Pharmacol Ther 2000;14:597-602.

105. Behary P, Cegla J, Tan TM, Bloom SR. Obesity: lifestyle management, bariatric surgery, drugs, and the therapeutic exploitation of gut hormones. Postgrad Med 2015;127:494-502.

106. Ardila-Hani A, Soffer EE. Review article: the impact of bariatric surgery on gastrointestinal motility. Aliment Pharmacol Ther 2011; $34: 825-831$.

107. Fernández-Esparrach G, Córdova H, Bordas JM, et al. [Endoscopic management of the complications of bariatric surgery. Experience of more than 400 interventions]. Gastroenterol Hepatol 2011;34:131-136. [Spanish]

108. Gumbs AA, Duffy AJ, Bell RL. Incidence and management of marginal ulceration after laparoscopic Roux-Y gastric bypass. Surg Obes Relat Dis 2006;2:460-463.

109. Filho AJ, Kondo W, Nassif LS, Garcia MJ, Tirapelle Rde A, Dotti CM. Gastrogastric fistula: a possible complication of Roux-en-Y gastric bypass. JSLS 2006;10:326-331.

110. Westling A, Bjurling K, Ohrvall M, Gustavsson S. Silicone-adjustable gastric banding: disappointing results. Obes Surg 1998;8: 467-474

111. de Jong JR, van Ramshorst B, Timmer R, Gooszen HG, Smout AJ. Effect of laparoscopic gastric banding on esophageal motility. Obes Surg 2006;16:52-58.

112. Merrouche M, Sabaté JM, Jouet P, et al. Gastro-esophageal reflux and esophageal motility disorders in morbidly obese patients before and after bariatric surgery. Obes Surg 2007;17:894-900.

113. Gutschow CA, Collet P, Prenzel K, Hölscher AH, Schneider PM. Long-term results and gastroesophageal reflux in a series of laparoscopic adjustable gastric banding. J Gastrointest Surg 2005;9:941948.

114. Ovrebo KK, Hatlebakk JG, Viste A, Bassøe HH, Svanes K. Gastroesophageal reflux in morbidly obese patients treated with gastric banding or vertical banded gastroplasty. Ann Surg 1998;228:51-58.

115. DuPree CE, Blair K, Steele SR, Martin MJ. Laparoscopic sleeve gastrectomy in patients with preexisting gastroesophageal reflux disease: a national analysis. JAMA Surg 2014;149:328-334.

116. Rebecchi F, Allaix ME, Giaccone C, Ugliono E, Scozzari G, Morino M. Gastroesophageal reflux disease and laparoscopic sleeve gastrectomy: a physiopathologic evaluation. Ann Surg 2014;260: 909-914; discussion 14-15.

117. Burgerhart JS, Schotborgh CA, Schoon EJ, et al. Effect of sleeve gastrectomy on gastroesophageal reflux. Obes Surg 2014;24:14361441. 